AGH DRILLING, OIL, GAS • Vol. 31 • No. 2 • 2014

http://dx.doi.org/10.7494/drill.2014.31.2.191

T. Bilstad*, B. Jensen**, M. Toft**

\title{
ENVIRONMENTAL FRIENDLY DRILLING FLUID MANAGEMENT OFFSHORE NORWAY
}

\section{INTRODUCTIONAND FUNDAMENTALS}

The first exploration well on the Norwegian Continental Shelf was drilled in 1966. Until 1980 diesel was used as the continuous phase in OBM drilling fluid. Discharge of drilled cuttings derived from OBM was allowed until 1993 [3]. After 1993 all cuttings from drilling and production of hydrocarbons using OBM has been classified as hazardous waste. Large improvements can be realized in the drilling fluid cycle by considering discarded fluids as a resource, not a waste. Current practize in the Norwegian Offshore Sector recovers OBM for reuse by extracting oil from cuttings onshore using different technologies.

The types of fluids utilized in drilling operations determine to which extent the cuttings are considered hazardous. The main categories of drilling fluids are oil based mud (OBM) and water based mud (WBM). Synthetic based mud (SBM) is a third option. The purpose of circulating fluids into wells during drilling operations are several; stabilize the well bore, control subsurface pressure and formation pressure, control well stability and corrosion, cool and lubricate the drill bit, and last but not least to carry the cuttings to the surface.

Drilled cuttings are rocks produced during drilling operations. They become coated with drilling fluids during transport to surface. Typical OBM drilled cuttings are composed of $70 \%$ mineral solids, $15 \%$ water and $15 \%$ oil by volume. OBM is typically based on either mineral oil or linear paraffin. The use of diesel in drilling fluids has been discontinued in Norwegian waters. One advantage of OBM over WBM is enhanced drilling performance, especially in technical challenging environments. A drawback, however, is the toxicity of OBM, prohibiting discharge of cuttings directly from shakers to the Norwegian marine environment. By

* Environmental Engineering, University of Stavanger, 4036, Norway

** Halliburton, Baroid Surface Solutions, Eldfiskveien 1, 4056 Norway 
comparison, however, in the Gulf of Mexico it is legal to dispose ofcuttings to the seabed containing $6.9 \%$ oil by weight.

Research showsthat OBM discharges are killing marine species and reducing biodiversity due to reducing oxygen in the water and clog the filter feeders. Spawning grounds for fish are damaged by drilling dischargeand so are Norway'scold water coral reefs (Lophelia pertusa).

Total fluid management (TFM) leads to environmental impact reduction (EIR). Minimization of drilling fluid consumption through reuse of fluids, leads to cost reduction. Volume of cuttings may be reduced through directional drilling and by drilling smaller diameter holes. Choice of drilling techniques that consumes less drilling fluid volumes provides cost savings. Use of fluids and additives with lower environmental impact is also an option. The common weighing agent barite $\left(\mathrm{BaSO}_{4}\right)$ contains heavy metals, and could be replaced by hematite $\left(\mathrm{Fe}_{2} \mathrm{O}_{3}\right)$ or illmenite $\left(\mathrm{FeTiO}_{3}\right)$. The same concern goes for chemical components of drilling fluids; i.e., toxicity, biodegradability, persistence, bioaccumulation and heavy metals.

A purpose of the thermo-mechanical cuttings cleaner (TCC) is to convert hazardous oily cuttings into useful products. TCC facilities are only available onshore in Norway, but are employed offshore in the British Sector negating the need for transport of cuttings to shore. Cuttings are allowed disposed to sea when no toxic fluids are attached. TCC separation is accomplished by generating temperatures of $240-300{ }^{\circ} \mathrm{C}$ sufficient for evaporation of oil and water from the mineral solids [4]. The temperature is sufficiently low to not crack the oil, thereby enabling reuse of oil coating the cuttings in new drilling fluid.More than $99 \%$ base oil recoveries with less than $2 \%$ solids are left in recovered oil. The recoverable byproducts include base oil, water and solids; i.e., cuttings. Using TCC offshore eliminates the need for transport of cuttings ashore as well as reduced human and environmental (HSE) exposures; improving health and safety.

\section{DRILLED CUTTINGS MANAGEMENT}

Historically, offshore produced cuttings have been disposed of at sea. However, environmental laws and regulations in Norway have since 1993 prohibited such practice when using OBM, and specifically when drilled cuttings exceed 1\% oil by weight [3] Drilled cutting particle size varies between $10 \mu \mathrm{m}$ and $20 \mathrm{~mm}$ depending on the drill bit, well bore length and geological formations. Depending on the quality of OBM, the geological formations and whether drilling is in hydrocarbon reservoir sections, cuttings are coated with different hydrocarbons including PAHs, PCBs, and heavy metals. Re-injection of cuttings as a slurry into subsurface formations has over the last few years been challenged due to several cases of loss of formation integrity, leading to migration of oil and water, leaks, cuttings re-entering the sea bed and collapsing formations. Such mishaps have developed into increased focus on proper design and maintenance of injection wells. The method of re-injection is however, still widely used (Figure 1). 


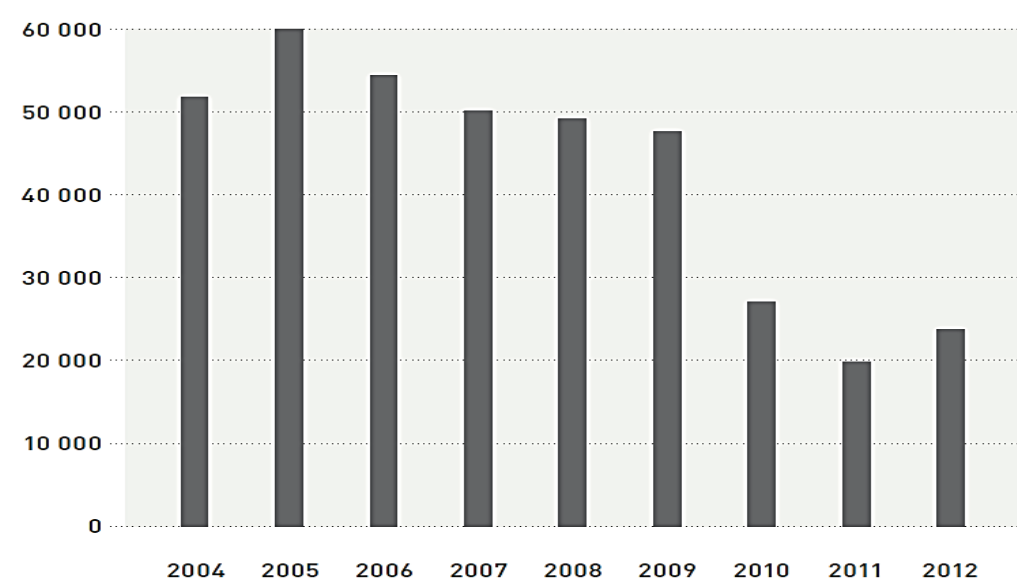

Fig. 1. Oil Based Drilled Cuttings Injection in Norwegian Sector (tonns/year)

WBM normally consists of environmental friendly chemicals, classified as green and yellow with regard to environmental toxicity, whichallows for direct discharge to sea. However, in environmental sensitive areas such as the Barents Sea, also WBM discharges are in many areas prohibited or subject to governmental approval and possible discharge permit. The Barents Sea is a "0-discharge area" and a permit is always required, also for sub-surface injection. Figure 2 shows the trend of using WBM in Norway.

Treatment of OBM drilled cuttings is initiated offshore by a shale shaker consisting of vibrating screens. Further solids control could include gravitational sand settling, a specialized desander and deciliter as well as centrifuges, all successively removing smaller solids from the mud. The shale shaker is the universal common separation technique for separating fluids from cuttings. Each well typically produces $300-1800$ tons from the shaker, with $5-15 \%$ by volume oil [2].

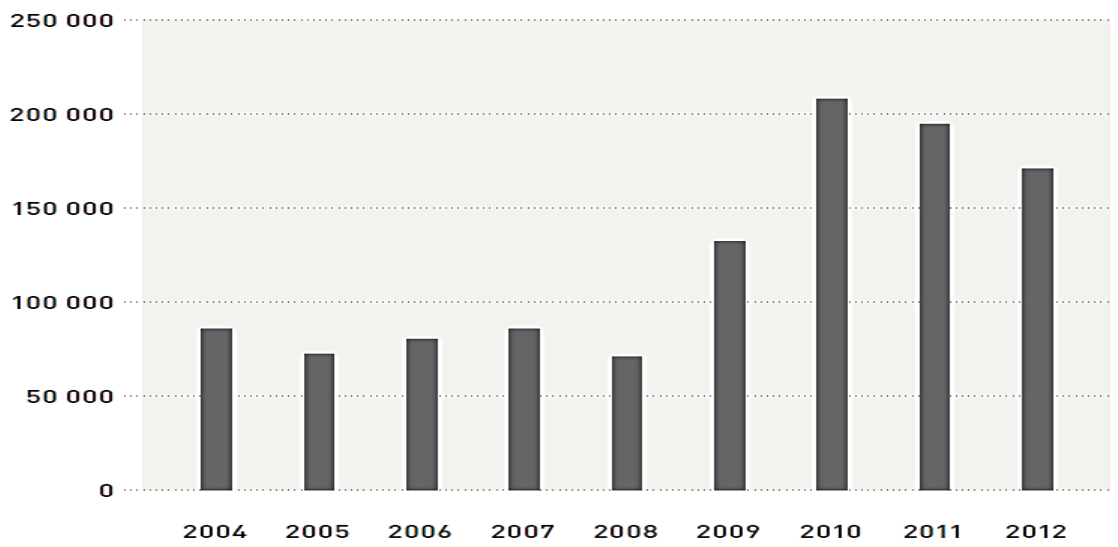

Fig. 2. Water Based Drilled Cuttings Disposed Offshore Norway (tonns/year) 
Depending on local regulations and oil content on cuttings, available disposal options include discharge to sea, underground injection, and further offshore and onshore treatment. In Norway permits are required for all discharges as well as sub-surface injection. Figure 3 summarizes three years of accumulated drilled cuttings mass production from the Norwegian

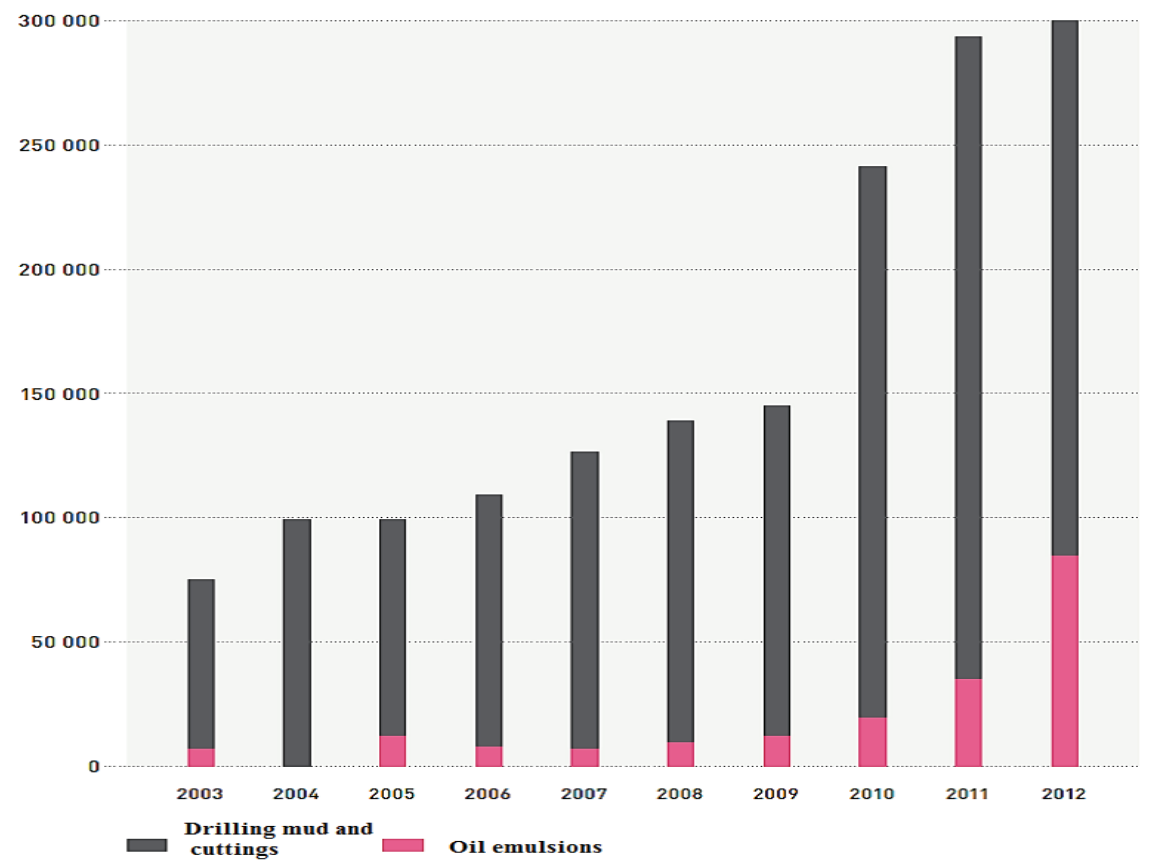

Fig. 3. Oil Based Drilled Cuttings, mud and oil emulsions transported to shore from Norwegian Offshore Sector (tonns/year)

offshore petroleum sector. Treatment of offshore generated drilled cuttings is a challenge compared with cuttings generated onshore. After shaker separation of mud and cuttings, the transport routes for the two components include internal transport on the rig itself, from the rig to vessel, further transport by vessel to onshore receiving facilities, and on to treatment facilities and possible reuse or final disposal. This is a cost issue of great concern; logistics and transportation of offshore drilled cuttings.

Figure 4 shows how Halliburton is arranging their cuttings transport tanks (CTT) going from the platform and on to a supply vessel. Figure 5 depicts a layout of a cuttings treatment plant. After the oily cuttings have been through the TCC unit in Figure 6, the recovered drill fluid is compared to virgin drill fluid in Figure 7.

Cleaning of OBM cuttings offshore or transport of cuttings to shore are alternative cuttings management practices. For logistics and cost reasons great emphasis is put on offshore waste minimization, including reuse or reutilization of mud. Majority of the amount shipped to shore go to one of tentreatment facilities along the Norwegian coast. 


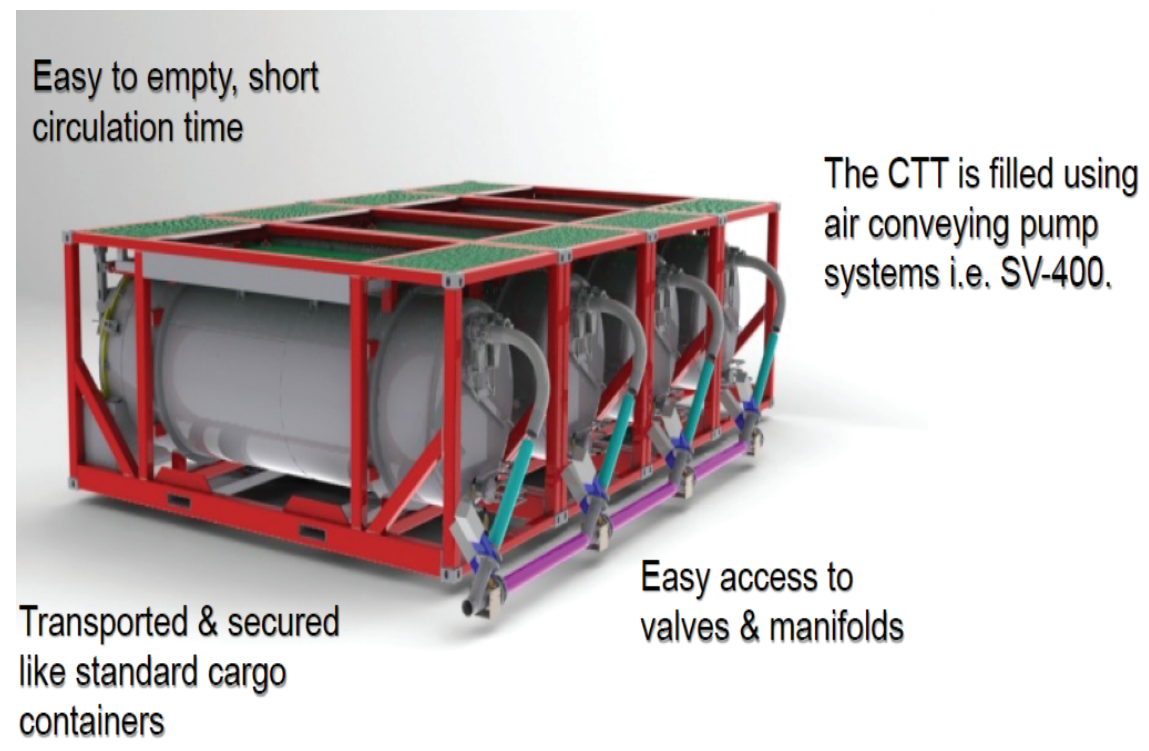

Fig. 4. Cuttings Transport Tank (CTT)

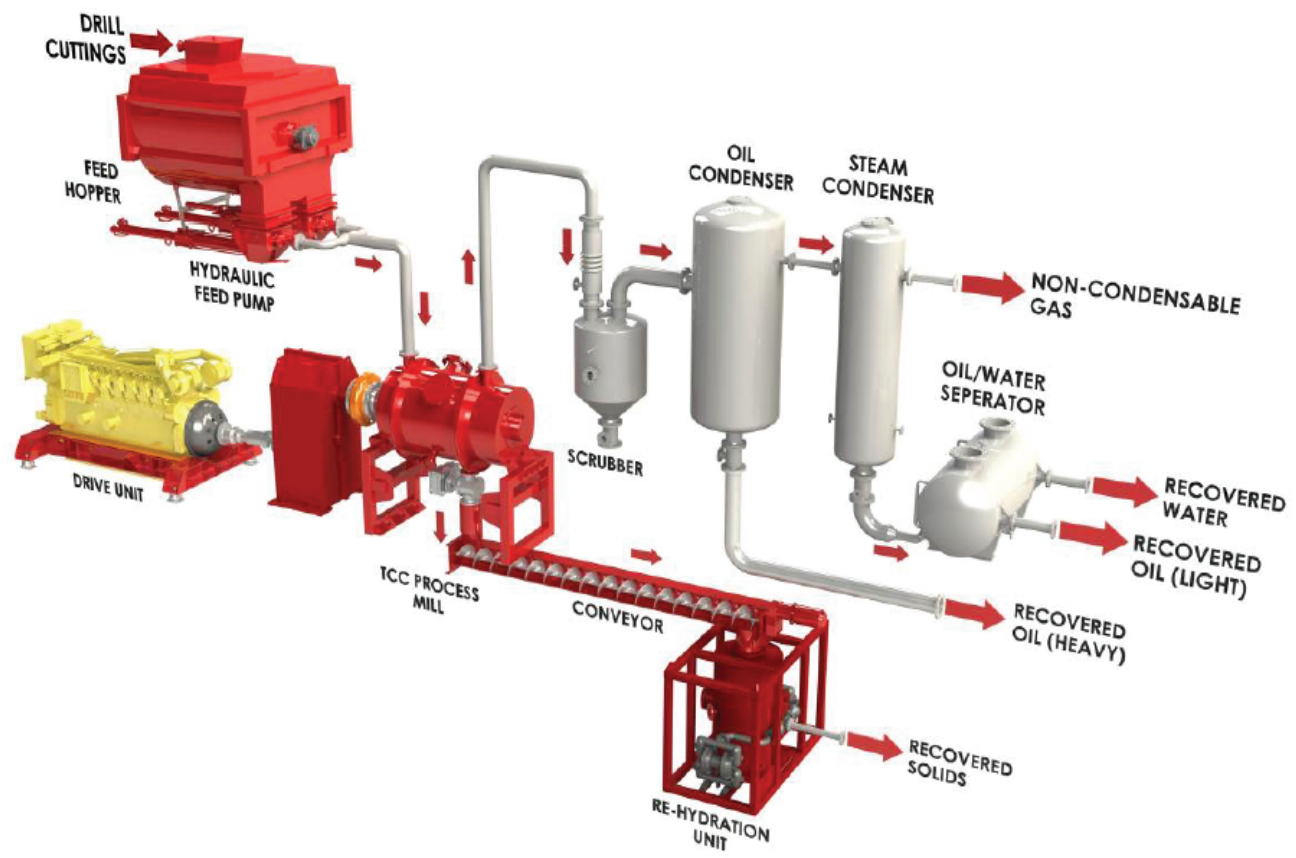

Fig. 5. Thermomechanical Cuttings Cleaner Flow Diagram 


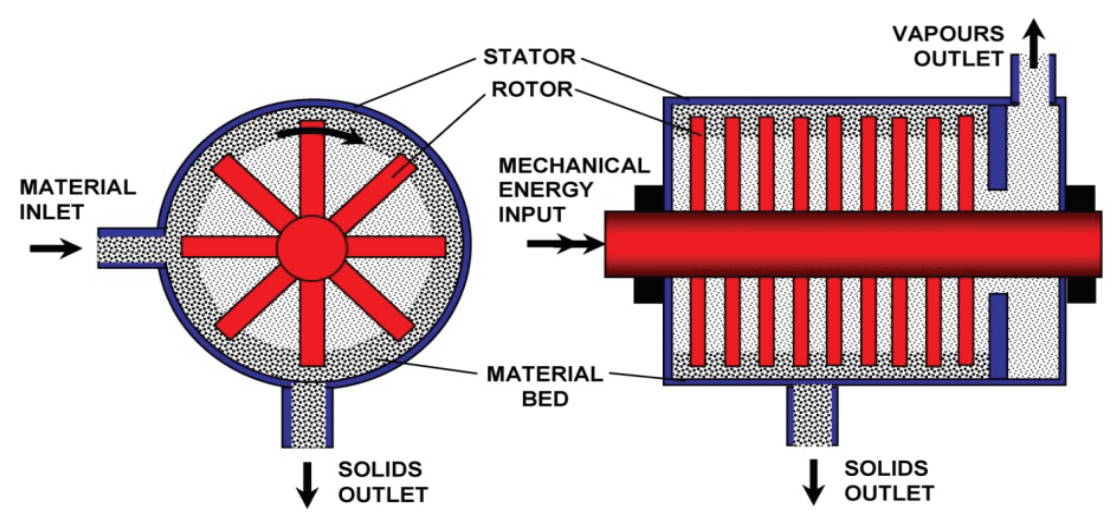

Fig. 6. The Principal of the Thermomechanical Cuttings ProcessMill
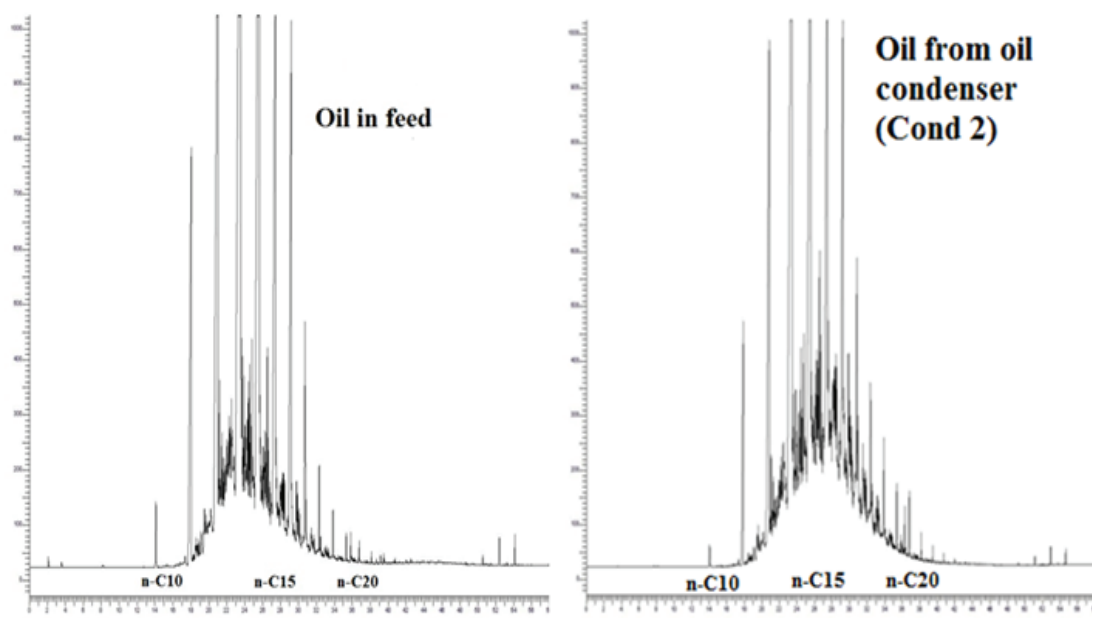

Fig. 7. Comparing virgin drill fluid with TCC treated fluid recovered for reuse

The process mill is the heart of the TCC separation process and converts kinetic energy to thermal energy by creating friction in the cuttings. Solids are recovered through an auger system, discharged through a cell valve as dry powder and on to rehydration, with recovery of water prior to disposal. Oil and water flash off as vapors, and are condensed and separated in a condenser skid. The water and crushed cuttings are cleaned to levels below Norwegian requirements for sea discharge, $30 \mathrm{mg} / \mathrm{l}$ oil in water and $1 \%$ oil by weight on cuttings.

The research leading to these results has received funding from the Polish-Norwegian Research Programme operated by the National Centre for Research and Development under the Norwegian Financial Mechanism 2009-2014 in the frame of Project Contract No. PolNor 200375/58/2013. 


\section{REFERENCES}

[1] Halliburton. Presentation by Bjørnung Jensen at Min-Novation Seminar, University of Stavanger, Norway April 26, 2012

[2] Jensen, Bjørnung. Presentation atDrilling and Well Technology Conference inKristiansand, Norway September 16-18, 2013

[3] NIVA. PAH-forurensning av sjøbunn - En oversikt over kunnskapsstatus Oslo. www. niva.no, 2010

[4] Thermtech. General Technical Files and Handbook. www.thermtech.no. Jacob Kjødes vei 15, 5232 Paradis, Norway, 2006 